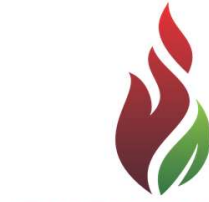

SUSTENERE

Publishing Corporation

\section{ALGAROBA (PROSOPIS JULIFLORA) NA CAATINGA NORTE-RIO-GRANDENSE: ANÁLISE DO MUNICÍPIO DE FERNANDO PEDROZA}

\section{RESUMO}

A biodiversidade presente na caatinga está sendo degradada de forma crescente. Entre os diversos fatores envolvidos nesse processo, a invasão de espécies exóticas no bioma, acelera os seus efeitos. A algaroba, que foi introduzida no Nordeste na década de 1940, é um exemplo de espécie considerada invasora. Nesse contexto, este estudo identificou os locais onde a espécie está presente e determinou a área ocupada por ela no território do município de Fernando Pedroza. Além disso, foi realizada uma comparação entre os locais onde foram identificadas as algarobas, no município e as áreas descritas, na bibliografia especializada, como suscetíveis ao alastramento da espécie no bioma. Para atingir o objetivo descrito foi realizada uma pesquisa bibliográfica e foram manipulados dados orbitais do satélite LANDSAT-8 que alimentaram um sistema de informação geográfica. Diante da análise dos mapas produzidos e dos dados discutidos, pode-se considerar que os resultados corroboram as informações advindas de diversos autores que indicam que a espécie está se alastrando na caatinga, principalmente em locais de solos de aluvião e de matas de galerias. No município a espécie está presente em 829 hectares.

PALAVRAS-CHAVE: Bioma; Invasão; Ilhas de Sucessão.

\section{CAROB TREE (PROSOPIS JULIFLORA) IN NORTH RIO GRANDE CAATINGA: ANALYSIS OF THE MUNICIPALITY OF FERNANDO PEDROZA}

\section{ABSTRACT}

The biodiversity present in the caatinga is being increasingly degraded. Among the many factors involved in this process, the invasion of exotic species in the biome, accelerates its effects. The Carob tree, which was introduced in the Northeast in the 1940s, is an example of species considered invasive. In this context, this study identified where the species is present and determined the area occupied by it in the municipality of Fernando Pedroza. In addition, a comparison between the places where the mesquite were identified was held in the city and the areas described in professional literature as susceptible to the spread of the species in the biome. To achieve the objective described was carried out a literature search and were manipulated satellite data from Landsat-8 satellite that fueled a geographic information system. Based on the analysis of maps produced and discussed data, it can be considered that the results support the arising of many authors information indicating that the species is spreading in the bush, especially in alluvial soils of local and gallery forests. In the county the species is present in 829 hectares.

KEYWORDS: Biome; Invasive; Succession of Islands.
Nature and Conservation Aquidabã, v.8, n.1, Nov, Dez 2014, Jan, Fev, Mar, Abr, Mai, Jun, Jul, Ago, Set, Out 2015.

ISSN 2318-2881

\section{SECTION: Articles}

TOPIC: Biossegurança

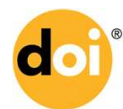

DOI: $10.6008 /$ SPC2318-2881.2015.001.0002

João Paulo Silva dos Santos Universidade do Estado do Rio Grande do Norte, Brasil http://lattes.cnpq.br/1998443990140968 joaozxz@yahoo.com.br

Marco Antonio Diodato

Universidade Federal Rural do Semi-Árido, Brasil http://lattes.cnpq.br/5771382429851385 diodato@ufersa.edu.br

Received: 30/09/2015

Approved: 30/09/2015

Reviewed anonymously in the process of blind peer.

Referencing this:

SANTOS, J. P. S.; DIODATO, M. A.. Algaroba (Prosopis juliflora) na caatinga norte-rio-grandense: análise do município de Fernando Pedroza. Nature and Conservation, Aquidabã, v.8, n.1, p.13-21, 2015. DOI: http://dx.doi.org/10.6008/SPC2318 2881.2015.001.0002 


\section{INTRODUÇÃO}

A caatinga é conceituada por Maia (2004) como uma floresta que, durante o período sem chuva, apresenta um aspecto esbranquiçado. Esse efeito é visualizado devido à queda, na época seca, das folhas da maioria das espécies nativas. Essa condição expõe as cascas claras das árvores que compõem a mata. Estima-se que, atualmente, $40 \%$ do território original do bioma ainda está coberto por vegetação nativa e que cerca de $80 \%$ dos seus ecossistemas originais já foram alterados (SOARES, 2011).

A biodiversidade presente na caatinga está sendo degradada de forma crescente para atender a um quadro de necessidades, que está sempre aumentando, o que promove um ciclo de constante de consumo dos recursos existentes. Em consequência da exploração, o bioma entrou em processo de empobrecimento biológico, apresentando uma drástica diminuição das espécies vegetais nativas (SOARES, 2011).

Entre os diversos fatores envolvidos no processo de degradação da caatinga, Lyra et al. (2009) apontam que a invasão de espécies exóticas no bioma, aceleram os seus efeitos. Nesse contexto, a Prosopis juliflora (Sw). D.C., conhecida como algaroba, é um exemplo de espécie considerada invasora.

Essa árvore é proveniente das regiões áridas e semiáridas das Américas, África e Ásia e faz parte do gênero Prosopis, grupo que contém 44 espécies conhecidas (MUNIZ, 2009). Altamente adaptada a regiões secas, a algaroba consegue sobreviver e se desenvolver em áreas com taxas pluviométricas entre 150 e $1.200 \mathrm{~mm}$ por ano. Essa condição Ihe permite resistir a extensos períodos de estiagens (SOARES, 2011).

A espécie leguminosa e não oleaginosa, foi introduzida no Nordeste brasileiro na década de 1940 com dois objetivos distintos. O primeiro deles era que as suas vagens servissem para alimentar os animais. O segundo estava relacionado a ações de reflorestamento de áreas desmatadas (MUNIZ, 2009).

A partir dessa introdução, a árvore propagou-se por toda área semiárida nordestina, ao ponto de passar a ser alvo de estudos sobre as suas relações ambientais com a caatinga. A partir disso, vários pesquisadores identificaram na dispersão da espécie no bioma, características de invasão biológica (NASCIMENTO, 2008; OLIVEIRA, 2006; PEGADO, 2004).

Um exemplo dessa consideração pode ser destacado em Oliveira (2006) quando o autor relaciona a espécie com o processo de invasão biológica na caatinga, principalmente nas áreas de várzeas, em matas de galerias e em locais com solos de aluvião. Nessas áreas a quantidade populacional da espécie forma verdadeiras matas ciliares. Em estimativa, o autor discorre que a área ocupada pela árvore, no bioma, pode chegar a um milhão de hectares, sendo que não existe um levantamento concreto sobre a área ocupada. O que se sabe é que existem grandes concentrações nos Estados do Rio Grande do Norte, Paraíba e Pernambuco, principalmente em 
áreas de intensas atividades antrópicas como em trechos de rodovias, próximo a rios, riachos e açudes (LIMA et al., 2005).

Nesse cenário, o município de Fernando Pedroza, que está inserido na caatinga norte-riograndense, em uma área de ocorrência da algaroba, foi selecionado para a realização deste estudo que identificou os locais onde a espécie está presente e determinou a área ocupada por ela no território do município. Além disso, foi realizada uma comparação entre os locais onde foram identificadas as algarobas e as áreas descritas, na bibliografia especializada, como suscetíveis ao alastramento da espécie no bioma.

\section{METODOLOGIA}

A área delimitada para a realização deste trabalho abrange toda a região município de Fernando Pedroza, que se encontra localizado na mesorregião Central Potiguar e na microrregião de Angicos. O território selecionado limita-se com os municípios de Angicos, Santana dos Matos e Lajes, abrangendo uma área total de $323 \mathrm{~km}^{2}$. O município tem sua sede localizada a uma altitude média de 133 m, estando situada nas coordenadas $05^{\circ} 41^{\prime} 49,2^{\prime \prime}$ de latitude sul e $36^{\circ} 31^{\prime} 51,6^{\prime \prime}$ de longitude oeste (BELTRÃO et al., 2005). A figura 1 demonstra a localização do município no Rio Grande do Norte. Fernando Pedroza foi selecionado para a realização desse estudo devido à quantidade de algarobas que podem ser encontradas, tanto na área urbana como rural do seu território.

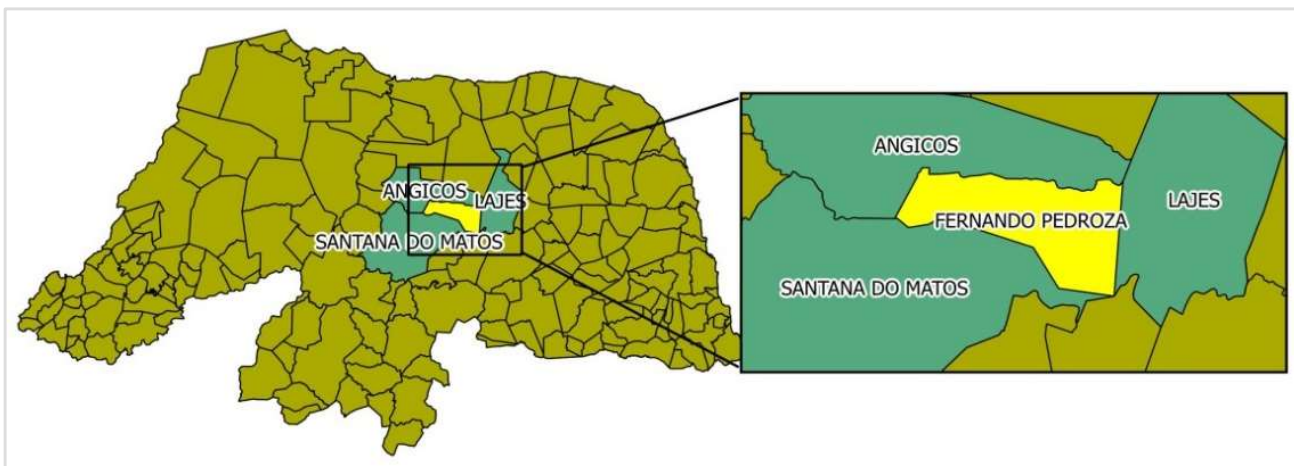

Figura 1: Localização do município de Fernando Pedroza no Rio Grande do Norte

Primeiramente, para a execução desse estudo foi realizado um levantamento bibliográfico em artigos científicos, dissertações, teses e documentos técnicos que relacionam a algaroba ao processo de invasão da caatinga. O resgate dessas informações teve como intuito verificar as principais características envolvidas na dispersão e as áreas do bioma onda a invasão da algaroba é comumente relatada. Secundariamente, foram manipulados dados orbitais do satélite LANDSAT8 que alimentaram um sistema de informação geográfica (SIG) formatado no programa Quantium Gis 2.2.0. 
Através do manuseio do software, foi criada uma composição colorida, formada pelas bandas 4R3G2B, com uma resolução espacial de 15 metros. As imagens utilizadas foram resgatadas pelos sensores do satélite no dia 04 de agosto de 2013, época do ano onde grande parte das espécies da vegetação nativa da caatinga está "esbranquiçada" devido à falta de chuva. Contrastando com esse efeito, a algaroba apresenta-se verde mesmo nos meses secos do ano.

A escolha das imagens no período de estiagem da região buscou facilitar a identificação dos locais de ocorrência da árvore, já que ao se realizar a composição colorida da imagem de recortes de caatinga, em uma resolução espacial de 15 metros, é possível verificar facilmente um contraste entre a vegetação nativa e espécie. Essa condição pode ser visualizada na figura 2, em uma escala de 1:110.000. No recorte foi destacada, através de uma linha preta pontilhada, uma área ocupada por algaroba.

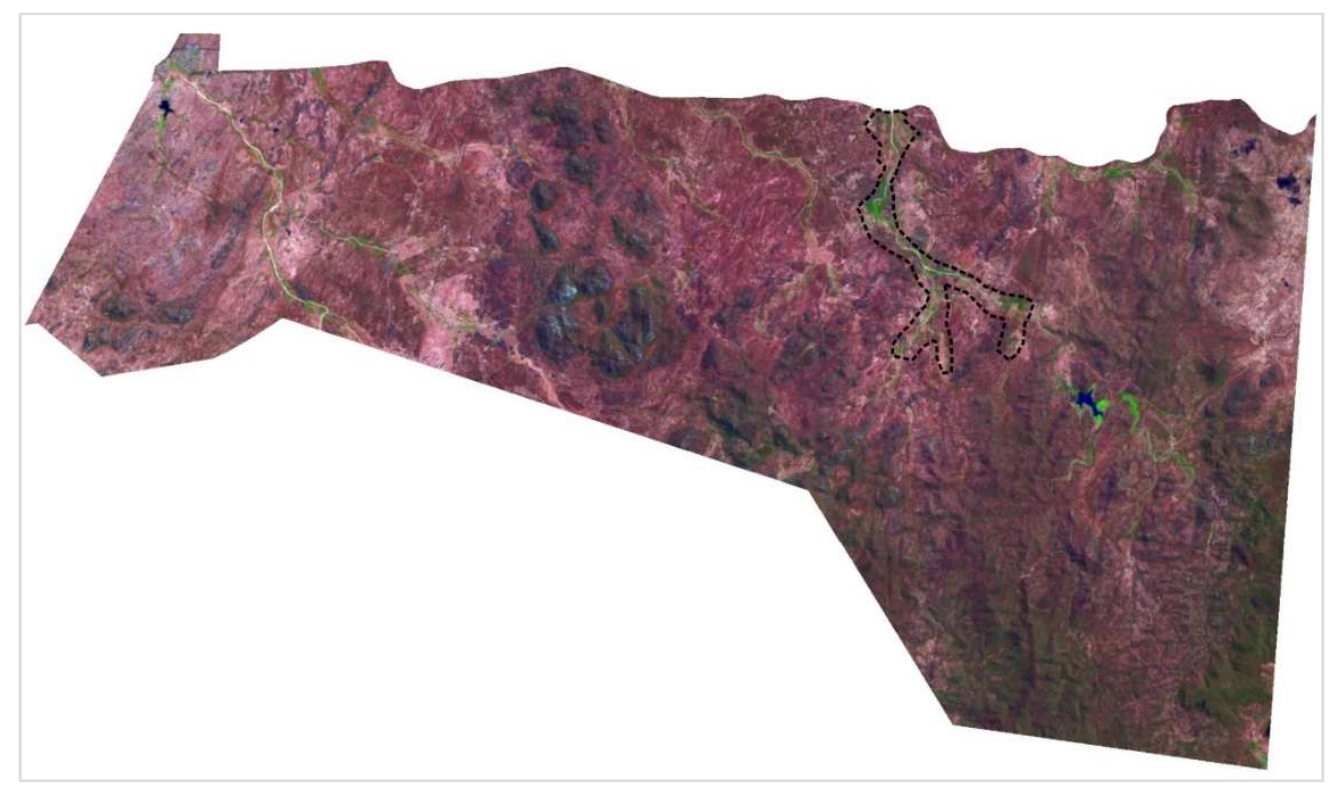

Figura 2: Composição colorida natural utilizada

Em estudos que envolvem imagens de satélite, o processamento digital de imagens é realizado para extrair, condensar e realçar a informação de interesse com o intuito de facilitar a identificação dos itens que fazem parte do objetivo da interpretação. (BRASIL, 2013).

Diversas técnicas são usadas para se realizar a interpretação digital de imagens. Elas são aplicadas de acordo com o Software SIG que será manuseado. Entretanto, as mais comumente utilizadas são as modificações realizadas com o contrataste e o brilho da imagem, a aplicação de filtros e a inserção de classificações multiespectrais. Além disso, também são utilizadas, de forma ampla, processos de classificação não supervisionada e supervisionada.

Nesse trabalho, primeiramente foram aplicados processo de filtragem que alteraram a saturação, o brilho e o contraste da imagem trabalhada, possibilitando o destaque das áreas com a presença da espécie. No segundo momento aplicou-se a técnica de classificação não supervisionada para realizar a distinção dos pixels da imagem, de acordo com a sua tonalidade de cor. Após a classificação, foi realizado um processo de vetorização dos pixels da imagem para que Nature and Conservation • v.8-n.1 • Nov, Dez 2014, Jan, Fev, Mar, Abr, Mai, Jun, Jul, Ago, Set, Out $P$ a g e | 16 2015 
fosse possível realizar a edição do mapa temático resultante da avaliação. Para isso foram criadas oito categorias de aglutinação dos vetores gerados que formaram as seguintes categorias de cobertura do território do município: algaroba, solo exposto, caatinga secundária, caatinga preservada, afloramentos rochosos e serras, açudes, recorte urbano e outras árvores.

Para a edição do mapa temático também foram utilizadas imagens advindas do software Google Earth com o intuito de eliminar dúvidas na interpretação em alguns pontos do recorte. As informações disponibilizadas pelo software citado, por sua grande abrangência, alta resolução espacial e facilidade na identificação de alvos, têm sido de grande valia para esse tipo de elucidação interpretativa de imagens de satélite. (BRASIL, 2013).

Também foram utilizados dados consolidados sobre os locais de drenagem pluvial das bacias hidrográficas do Estado do Rio Grande do Norte. Dessa forma foi possível comparar as informações dos locais onde se identificou a espécie com as áreas de drenagem das águas pluviais existentes dentro do território do município.

\section{RESULTADOS}

Através da avaliação das imagens processadas foi possível identificar que as regiões onde existe e a presença da espécie no município estão localizadas, principalmente, nas áreas de drenagem de águas pluviais, o que pode ser visualizado na figura 3.

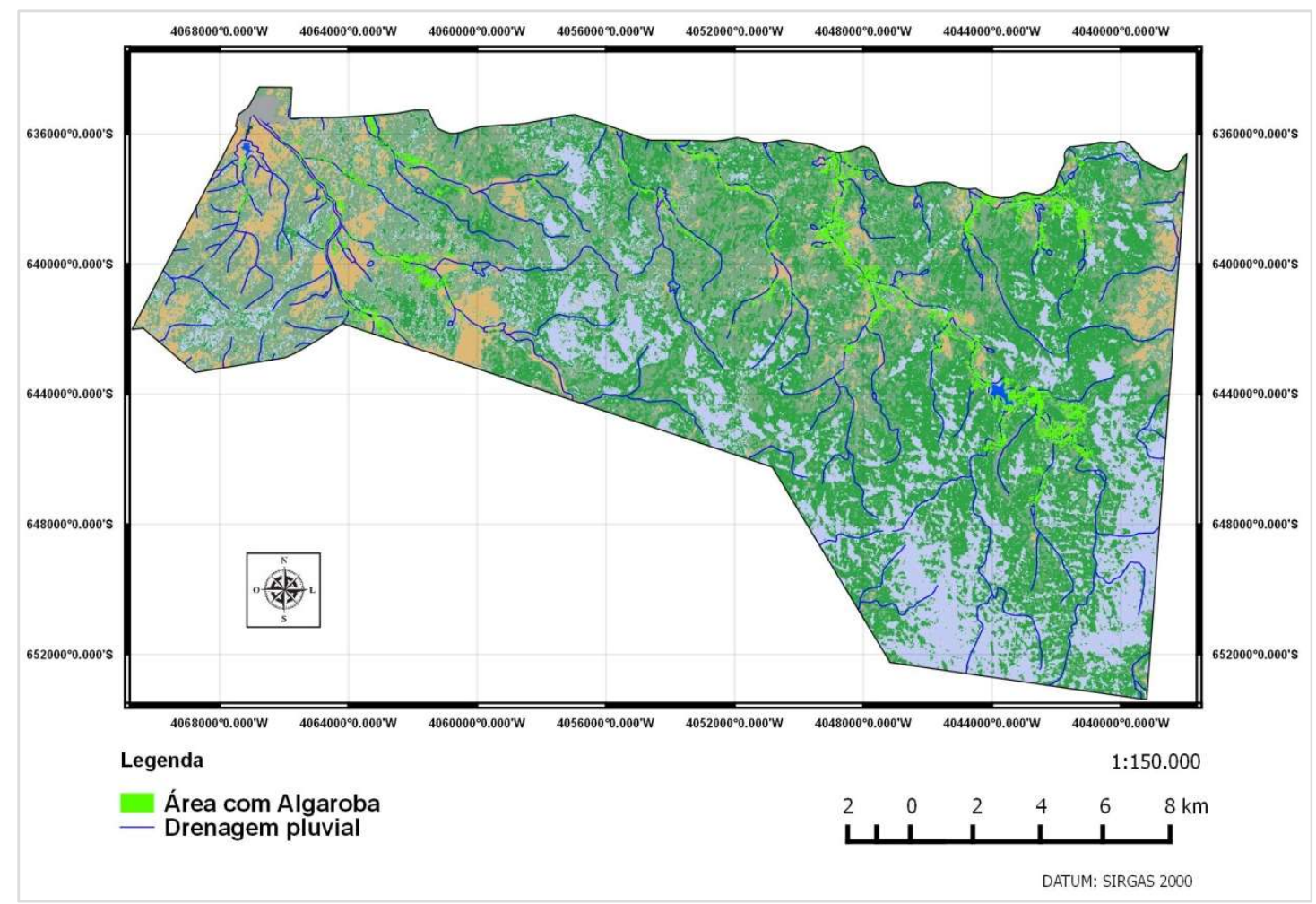

Figura 3: Presença da espécie nas áreas de drenagem pluvial do município 
Outro resultado identificado com a análise dos mapas gerados foi à presença de grandes concentrações da espécie em alguns recortes do município analisado, como pode ser visualizados na figura 4.
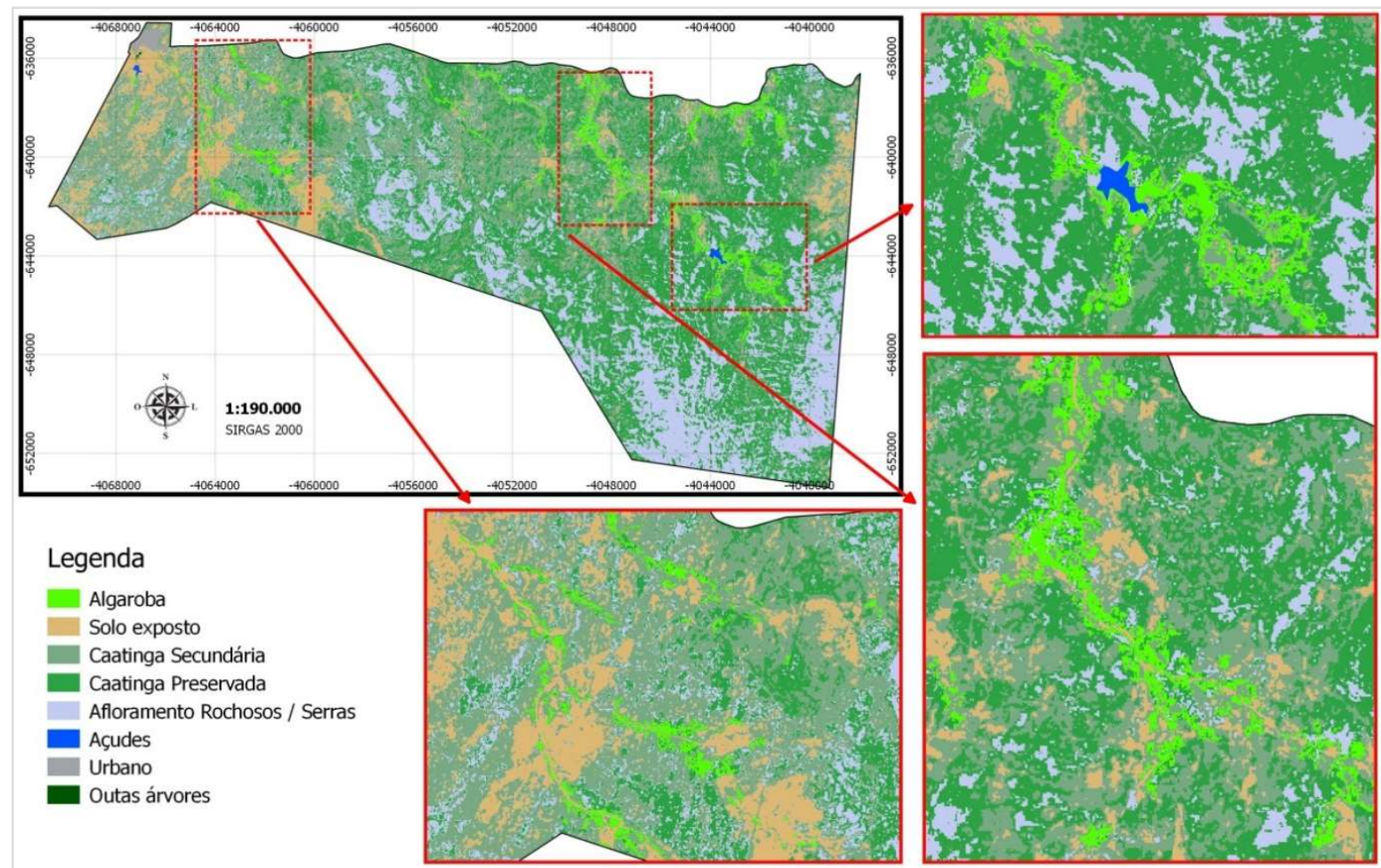

Figura 4: Área com denso povoamento de algaroba

Atualmente, a árvore está dispersa por 829 hectares da área total do município. Na figura 5 estão dispostas a quantificações das áreas que foram alvos da análise espacial que resultou na identificação e quantificação das áreas do município com a presença da espécie.

\section{DISCUSSÃO}

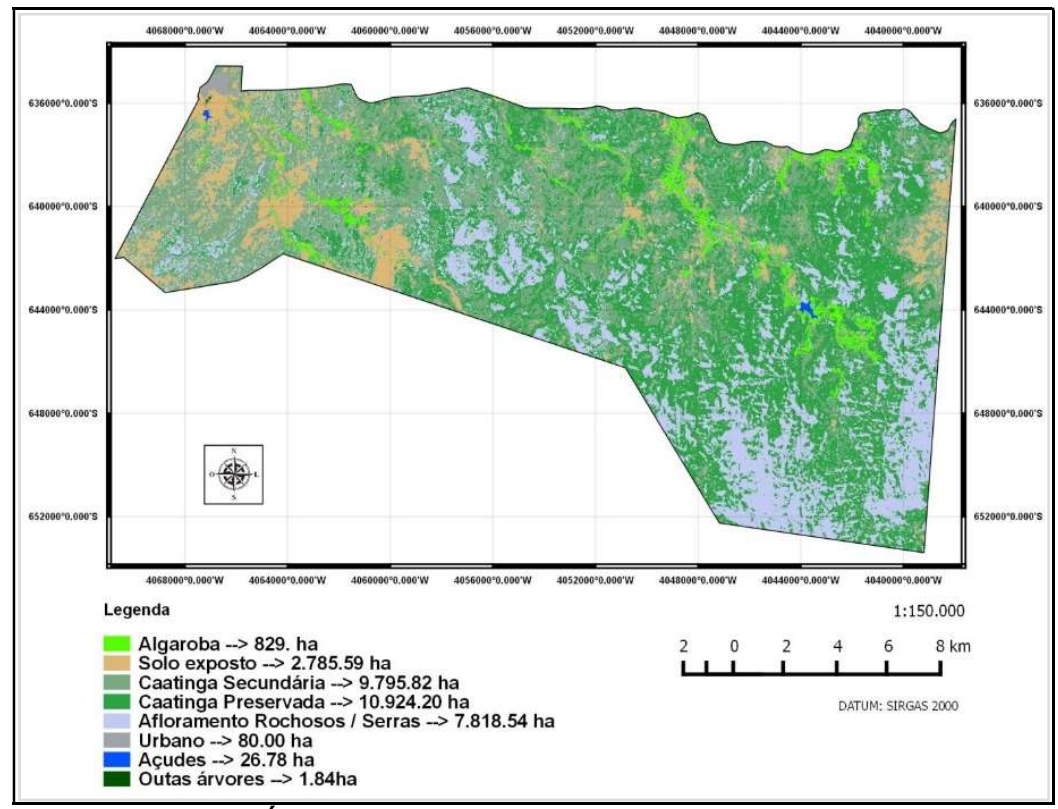

Nature and Conservation • v.8 - n.1 • Nov, Dez 2014, Jan, Fev, Mar, Abr, Mai, Jun, Jul, Ago, Set, Out 
A constatação apresentada na figura 4 corrobora a informação descrita por, Pegado (2004). Em seu trabalho o autor afirma que a espécie ocupa, preferencialmente, as matas ciliares, de galerias e os recortes de neossolos flúvicos. Ele cita que, nesses locais a algaroba forma populações de alta densidade ao se aproveitar da umidade contida no solo.

Com esse mesmo entendimento, Nascimento (2008), discorre que um dos fatores envolvidos no comportamento invasor de algaroba está relacionado à sua grande capacidade de realizar o aproveitamento da água e dos nutrientes existente nas áreas de drenagem das águas das chuvas em solos de aluvião. Para ele a espécie aproveita muito bem a umidade presente nessas áreas no processo de germinação em épocas de seca intensa.

Sobre esse processo Pasiecznik (2004) comenta que outro fator do sucesso da expansão das espécies do gênero Prosopis na caatinga é a presença de dois sistemas radiculares que se desenvolvem rapidamente após germinação, possibilitando as árvores atingirem até $40 \mathrm{~cm}$ de altura, em até oito semanas.

O comportamento das raízes da algaroba também é um item associado avanço da árvore na caatinga. Um dos dois sistemas radiculares da espécie adentra vários metros no solo e o outro se distribui superficialmente, formando um agrupamento de raízes adventícias especialistas em realizar o aproveitamento da água armazenada no solo (PASIECZNIK, 2004). A partir dessa constatação Nascimento (2008) afirma que esses fatores possibilitam a espécie uma absorção de nutrientes e de água mais eficiente do que as espécies nativas do bioma.

Relativos a essa característica de alastramento da espécie Mwangi e Swallow (2005) relatam que a $P$. juliflora tem essa capacidade por ser altamente agressiva, em comparação com as espécies nativas. Segundo eles, a árvore expele substâncias químicas de suas folhas que prejudicam a germinação e crescimento de plantas de colheitas, ervas más e outras espécies vegetais arbóreas. Noor et al. (1995) comentam que essas substâncias, por meio de efeitos alelopáticos, provocam atraso, reduz a germinação e também afetam negativamente as raízes, rebentos e o crescimento de plântulas de outras espécies.

$\mathrm{Na}$ caatinga, verificando o potencial de competição da algaroba, Nascimento (2008), constatou que a árvore reduziu o crescimento das espécies nativas em relação à área foliar, ao diâmetro e a altura, assim como aumentou a mortalidade das espécies nativas em ambientes com disponibilidade de água.

Com esses atributos, as primeiras algarobas, que se estabelecem, criam "ilhas de sucessão" que melhoram as condições ambientais do local para a sua propagação. Esse processo permite o crescimento gradativo do número de indivíduos em uma área, até a estabilização, ao longo do tempo, de um novo ecossistema (ARCHER, 1995).

Considerando os dados discutidos e do mapa constante na figura 5 pode-se constatar o processo de "ilhas de sucessão" em áreas do município de Fernando Pedroza. 


\section{CONCLUSÕES}

Diante da análise dos mapas produzidos e dos dados discutidos pode-se considerar que os resultados corroboram as informações advindas de diversos autores que indicam que a espécie está se alastrando na caatinga, principalmente em locais de solos de aluvião e de matas de galerias.

Também fica claro que a algaroba está se dispersando através do processo de "ilhas de sucessão", pois a grande quantidade de indivíduos, em algumas áreas do município, está criando condições para que a árvores estabeleçam condições ideais para se dispersarem.

Por fim, o trabalho demonstrou que, através de imagens de satélites, é possível verificar e determinar os resultados dos fenômenos envolvidos no processo de alastramento da algaroba na caatinga.

\section{REFERÊNCIAS}

ARCHER, S.. Herbivore mediation of grass-woody plant interactions. Tropical Grasslands, Texas, v.29, n.1, p.218-235, 1995.

BELTRÃO, B. A.; ROCHA, D. E. G. A.; MASCARENHAS, J. C.; JUNIOR, L. C. S.; PIRES, S. T. M.; CARVALHO, V. G. D.. Projeto cadastro de fontes de abastecimento por água subterrânea estado do Rio Grande do Norte. Recife: CPRM, 2005.

BRASIL. Manual Técnico de Uso da Terra. Rio de Janeiro: IBGE, 2013.

LIMA, P. L. F.. Manejo de áreas individuais de Algaroba. Petrolina: Embrapa Semi-Árido, 2005.

LYRA, L. H. B.; LIMA D. L.; SILVA, S. S.; XAVIER, T. S.; LIMA, V. C.. A questão do semi-árido e o bioma Caatinga. Viçosa: UFV, 2009.

MAIA, G. N.. Caatinga: árvores e arbustos e suas utilidades. São Paulo: Computação, 2004.

MUNIZ, M. B.. Processamento das vagens de algaroba (Prosopis juliflora) para produção de bioprodutos. Tese (Doutorado em Engenharia de Processos) - Universidade Federal de Campina Grande, Campina Grande, 2009.

MWANGI, E.; SWALLOW, B.. Invasion of prosopis juliflora and local livelihoods: case study from the Lake Baringo area of Kenya. Nairobi: World Agroforestry Centre, 2005.

NASCIMENTO, C. E. S.. Comportamento invasor da algarobeira Prosopis juliflora (Sw) D.C. nas planícies aluviais da caatinga. Tese (Doutorado em Biologia Vegetal) - Universidade Federal de Pernambuco, Recife, 2008.

NOOR, M.; SALAM, U.; KHAN, M. A.. Allelopathic effects of Prosopis juliflora Swartz. Journal of Arid Environments. Amsterdam, p.83-90., 1995.

OLIVEIRA, F. X.. Impactos da invasão da algaroba - Prosopis juliflora (sw.) dc. - sobre o componente arbustivo-arbóreo da caatinga nas microrregiões do Curimataú e do Seridó nos estados da Paraíba e do Rio Grande do Norte. Dissertação (Mestrado em Agronomia) - Universidade Federal da Paraíba, Areia, 2006.

PASIECZNIK, N. M.; HARRIS, P. J. C.; SMITH, S. J.. Identifying tropical prosopis species: a field guide. Coventry: HDRA, 2004. 
PEGADO, C. M. A. Efeitos da invasão da algaroba [Prosopis juliflora (S.W.) D. C.] sobre a composição florística e a estrutura da caatinga no Município de Monteiro(PA). Dissertação (Mestrado em Agronomia) - Universidade Federal da Paraíba, Areia, 2004.

SOARES, K. A. B.. Perfil do uso da lenha no ramo de produtos alimentícios na cidade de Patos(PB). Dissertação (Mestrado) - Universidade Federal de Campina Grande, Patos, 2011. 